\title{
Estrutura Genética da Raça Sindi no Brasil
}

\section{Fábio José Carvalho Faria1 ${ }^{1}$ Anibal Eugênio Vercesi Filho², Fernando Enrique Madalena ${ }^{3}$, Luiz Antônio Josahkian ${ }^{4}$}

\begin{abstract}
RESUMO - O objetivo deste trabalho foi descrever a estrutura genética da raça Sindi no Brasil, utilizando dados do registro genealógico de animais nascidos entre 1955 e 1998. O banco de dados foi separado nos seguintes períodos: 1979-1983, 1984-1988, 1989-1993 e 19941998. A endogamia total aumentou de 0,38 para 10,13\%; a esperada sob acasalamento ao acaso, de 0,07 para 5,65\%; e a endogamia atribuída à subdivisão populacional, de 0,30 para 4,74\%, considerando os períodos inicial e final, indicando a existência de subdivisão genética na raça Sindi. O tamanho efetivo populacional estimado pelo coeficiente total de endogamia decresceu vertiginosamente de 161 para 9. Tendo-se como base a probabilidade de origem do gene, foram calculados os números efetivos de fundadores, de ancestrais e de genomas remanescentes, os quais decresceram, ao longo do período total, atingindo valores de 16, 9 e 7, respectivamente.
\end{abstract}

Palavras-chave: estrutura genética, probabilidade de origem do gene, Sindi, tamanho efetivo populacional

\section{Genetic Structure of the Red Sindhi Breed in Brazil}

ABSTRACT - The aim of this research was to describe the genetic structure of the Brazilian Red Sindhi breed using pedigree records from registered animals born from 1955 to 1998. The data file was separated in the following periods: 1979-1983, 1984-1988, 19891993 and 1994-1998. The total inbreeding increased from 0.38 to $10.13 \%$, the expected inbreeding under random mating increased from 0.07 to $5.65 \%$, and the inbreeding due to population subdivision increased from 0.30 to $4.74 \%$, from the first to the final period, indicating that genetic subdivision in the Red Sindhi breed is relevant. The effective population size was estimated from the total inbreeding and decreased vertiginously from 161 to 9 . Based on probabilities of gene origin the effective numbers of founders, ancestors and remaining genomes were calculated and decreased over the total period, reaching values of 16, 9 and 7, respectively.

Key Words: genetic structure, probability of gene origin, Red Sindhi, effective population size

\section{Introdução}

A raça Sindi é originária do Estado de Sind no Paquistão e, graças à sua reputação em rusticidade e tolerância ao calor, se espalhou pela Ásia, Oceania, África e Américas. Os animais Sindi caracterizam-se por pequeno porte e pelagem vermelha, que pode variar em tonalidades, de acordo com o sexo do animal. As fêmeas produzem, em média, $1.700 \mathrm{~kg}$ de leite por lactação. Entretanto, sob condições ótimas, algumas chegam a ultrapassar $4.000 \mathrm{~kg}$ de leite por lactação (Leite et al., 2001).

Os primeiros exemplares dessa raça chegaram ao Brasil em 1952 e, atualmente, a maior parte do rebanho está presente no nordeste brasileiro (Leite et al., 2001). Desde sua introdução, o gado Sindi brasileiro manteve-se concentrado em poucos rebanhos, não apresentando a evolução numérica verificada em outras raças, mantendo o rebanho nacional reduzido. De acordo com Faria et al. (2001), o número, estimado em menos de 1.000 fêmeas puras em reprodução, classifica a raça no patamar crítico em relação ao risco de extinção, conforme critérios adotados pela FAO - Food and Agriculture Organization of the United Nations.

Este trabalho foi conduzido com o objetivo de quantificar a variabilidade genética da raça Sindi, por meio de informações de seu registro genealógico, com o intuito de fornecer subsídios para programas de preservação e expansão da raça.

\footnotetext{
${ }^{1}$ Professor Visitante do Depto. de Produção Animal da UFMS, Cidade Universitária s/n, Cx. P. 549, CEP 79070-900, Campo Grande MS. E-mail: cifal_ms@yahoo.com.br

2 Aluno de Doutorado em Ciência Animal, Departamento de Zootecnia, Escola de Veterinária da UFMG, Av. Antônio Carlos, 6627, Cx. P. 567, CEP 30123-970, Belo Horizonte - MG.

3 Professor do Departamento de Zootecnia, Escola de Veterinária da UFMG, Av. Antônio Carlos 6627, Cx. P. 567, CEP 30123-970, Belo Horizonte - MG. E-mail: fermadal@dedalus.Icc.ufmg.br

${ }^{4}$ Superintendente técnico da Associação Brasileira de Criadores de Zebu, Praça Vicente Rodrigues da Cunha, 110 BI 1 , CEP 38022 330, Uberaba - MG. Professor de Melhoramento Animal da Faculdade de Agronomia e Zootecnia de Uberaba - FAZU.
} 


\section{Material e Métodos}

Foram utilizados os dados do registro genealógico da raça Sindi, disponíveis sob processamento eletrônico, da Associação Brasileira de Criadores de Zebu (ABCZ). O arquivo de dados consistiu de 4.884 observações entre os anos de 1955 a 1998, referentes a amostragem de 8.080 registros (ABCZ, 2001). As informações referentes a cada animal consistiam de: pai, mãe, sexo, categoria de registro $(\mathrm{PO}=$ puro de origem / LA = livro aberto), dia, mês e ano de nascimento, criador e proprietário. Inicialmente, foram geradas estatísticas descritivas de cada amostra populacional e, em seguida, procedeu-se à separação do banco de dados em períodos, compreendendo os anos de 1979-1983, 1984-1988, 1989-1993 e 19941998. Otamanho efetivo populacional $\left(\mathrm{N}_{\mathrm{e}}\right.$ ) foi estimado por meio da taxa de variação dos coeficientes médios de endogamia entre gerações sucessivas, $(\Delta \mathrm{F})$, conforme Falconer \& Mackay (1996):

$$
\begin{gathered}
\Delta F=\frac{F_{t}-F_{t-1}}{1-F_{t-1}} \text {, com rearranjos: } \\
N_{e}=\frac{1}{2 \Delta F},
\end{gathered}
$$

em que: $F_{t}=$ coeficiente médio de endogamia estimado na geração atual; $F_{t-1}=$ coeficiente médio de endogamia estimado na geração anterior.

A estimação dos parâmetros baseados na probabilidade de origem do gene e o coeficiente de endogamia foram obtidos por meio da utilização do pacote PEDIG ${ }^{\circledR}$, que apresenta vários programas escritos em linguagem FORTRAN, gentilmente cedido pelo Dr. Didier Boichard (INRA - Station de Génétique Quantitative et Appliquée). O número efetivo de fundadores representa o número de animais com igual contribuição que produziria a mesma variabilidade genética encontrada na população estudada (Lacy, 1989). A aproximação clássica na determinação do número efetivo de fundadores foi obtida por:

$$
N_{\text {fun }}=\frac{1}{\sum_{k=1}^{f} q_{k}^{2}}
$$

em que $N_{\text {fun }}=$ número efetivo de fundadores; $\sum_{k=1}^{f} q_{k}^{2}=$ somatório da contribuição esperada do número de progênies (q) do fundador $k$ na população.
O número efetivo de ancestrais representa o número mínimo de animais (fundadores ou não) necessário para explicar a total diversidade genética da população estudada (Boichard et al., 1997). A determinação do número efetivo de ancestrais foi obtida computando-se a contribuição marginal de cada ancestral por:

$$
N_{\text {anc }}=\frac{1}{\sum_{k=1}^{f} p_{k}^{2}}
$$

em que $N_{a n c}=$ número efetivo de ancestrais; $\sum_{k=1}^{f} p_{k}^{2}=$ contribuiçãomarginaldo ancestral $k$ napopulação.

O número efetivo de genomas remanescentes representa o número de fundadores com igual contribuição que não teria perda de alelos fundadores por deriva genética na progênie e que produziria a mesma diversidade genética que a encontrada na população estudada (Lacy, 1989). O programa simulou segregações para cada progênie, gerando genótipos em função da amostragem aleatória de um alelo em cada progenitor, e as freqüências $f_{k}$ foram determinadas por contagem na população referência. $\mathrm{O} N_{\text {gen }}$ foi determinado em função da média de 1.000 simulações de segregações gênicas.

$$
N_{g e n}=\frac{N_{a}}{2}=\frac{1}{2} \sum_{k=1}^{2 f} f_{k}^{2}
$$

em que $N_{\text {gen }}=$ número efetivo de genomas remanescentes; $N_{a}=$ número efetivo de alelos (Crow \& Kimura, 1970).

Foram calculados o número médio de ancestrais, a proporção de ancestrais identificados por geração e o número equivalente de gerações completas, definido pela soma entre todas as gerações da proporção de ancestrais identificados em cada geração. Todas essas estatísticas foram computadas para indivíduos com pelo menos um ancestral identificado. O número equivalente de gerações completas foi dado por:

$$
\frac{1}{N} \sum_{j=1}^{N} \sum_{i=1}^{n_{j}} \frac{1}{2_{g i j}}
$$

em que $n_{j}=$ total de ancestrais do animal $j$; $g_{i j}=$ número de gerações entre o indivíduo $j$ e seu ancestral $i ; \mathrm{N}=$ total de animais na populaçãoreferência. 
As estatísticas de $\mathrm{F}\left(\mathrm{F}_{\mathrm{IT}}, \mathrm{F}_{\mathrm{ST}}\right.$ e $\left.\mathrm{F}_{\mathrm{IS}}\right)$ de Wright (1965) também foram calculadas. $F_{\text {IT }}$ o o coeficiente médio de endogamia da população, $\mathrm{F}_{\mathrm{ST}}$ designa $\mathrm{o}$ coeficiente médio de endogamia esperado se os reprodutores de cada período fossem acasalados aleatoriamente e foi estimado em populações hipotéticas produzidas pelo acasalamento ao acaso dos pais dentro de cada período por meio do programa escrito em linguagem FORTRAN, gentilmente cedido pelo Dr. Tetsuro Nomura (Kyoto Sangyo University), e $\mathrm{F}_{\text {Is }}$ expressa o desvio da casualidade nos acasalamentos, obtido como:

$$
F_{I S}=\frac{F_{I T}-F_{S T}}{1-F_{S T}}
$$

Se $\mathrm{F}_{\text {IS }}>0$, então a endogamia real ultrapassa o nível esperado sob acasalamentos ao acaso, implicando que os acasalamentos estão acontecendo entre animais mais aparentados que a média, conseqüentemente a população estará dividida em subpopulações. Quando $\mathrm{F}_{\text {IS }}<0$, evita-se a endogamia ou predomina o acasalamento entre subpopulações.

\section{Resultados e Discussão}

Determinaram-se o coeficiente de endogamia, a taxa de incremento $(\Delta \mathrm{F})$ e o $\mathrm{N}_{\mathrm{e}}$, que podem ser visualizados na Figura 1. Os valores calculados do primeiro ao último período foram de 0,$38 ; 3,16 ; 6,20$ e $10,13 \%$ para o $\mathrm{F}_{\mathrm{IT}}$, que expressa o coeficiente de endogamia; de 0,$3 ; 2,3 ; 3,5$ e $5,1 \%$ para o $\Delta \mathrm{F}$, que expressa a taxa de incremento da endogamia; e de 161, 20, 14 e 9 para o $\mathrm{N}_{\mathrm{e}}$. A endogamia e a taxa de incremento foram crescentes do primeiro ao último período, ao passo que o $\mathrm{N}_{\mathrm{e}}$ decresceu vertiginosamente, o que traz preocupações quanto a manutenção da variabilidade genética dessa raça.

Dos 4.981 animais do arquivo de genealogia, 1.611 apresentaram coeficiente de endogamia positivo, com média de 13,23\% e máximo de 42,96\%. Na Tabela 1, são apresentados os números de animais distribuídos por classe de endogamia.

O coeficiente total de endogamia apresentou-se em nível crítico, atingindo no último período 10,13\%, com crescimento da ordem de 33 vezes em relação ao valor do primeiro período. O coeficiente de regressão linear do F médio anual, ponderado pelo número de animais, foi estimado em 0,007 $(\mathrm{P}<0,05)$. O gráfico dos valores observados e preditos do coeficiente de endogamia podem ser visualizados na
Figura 2. Os valores dos parâmetros que expressam a variabilidade genética descritos para essa raça são críticos, e puderam ser confirmados em seguida por meio das análises baseadas na probabilidade de origem do gene.

Goddard \& Smith (1990) sugerem $\mathrm{N}_{\mathrm{e}}$ mínimo de 40 por geração para maximizar o ganho genético em população selecionada para produção de leite, e Meuwissen \& Woolliams (1994) recomendam valores entre 30 e 250 para prevenir decréscimo no valor adaptativo. Nicholas (1980) propõe valor mínimo de 50 por geração para o $\mathrm{N}_{\mathrm{e}}$. Nesse contexto, esse grupamento apresenta valores assaz reduzidos em comparação às recomendações da literatura.

Na Figura 3, pode-se observar a evolução anual do número de indivíduos endogâmicos em relação ao ano de nascimento na raça Sindi. Nesse período, pode-se verificar que, em 1979, não foram registrados animais endogâmicos. Entretanto, nos últimos três anos a quase totalidade dos animais é endogâmica.

Tabela 1 - Distribuição de animais da raça Sindi, conforme a classe de endogamia

Table 1 - Distribution of Red Sindhi animals, according to the inbreeding class

\begin{tabular}{cccc}
\hline $\begin{array}{c}\text { Classe de } \mathrm{F}_{\mathrm{IT}} \\
(\%)\end{array}$ & $\begin{array}{c}\text { Animais } \\
(\mathrm{n})\end{array}$ & $\begin{array}{c}\text { Classe de } \mathrm{F}_{\mathrm{IT}} \\
(\%)\end{array}$ & $\begin{array}{c}\text { Animais } \\
(\mathrm{n})\end{array}$ \\
$\begin{array}{c}\text { Class of } F_{I T} \\
(\%)\end{array}$ & $\begin{array}{c}\text { Animals } \\
(\mathrm{n})\end{array}$ & $\begin{array}{c}\text { Class of } F_{I T} \\
(\%)\end{array}$ & $\begin{array}{c}\text { Animals } \\
(\mathrm{n})\end{array}$ \\
\hline 0 & 3.370 & $20-25$ & 79 \\
$0-5$ & 136 & $25-30$ & 105 \\
$5-10$ & 383 & $30-35$ & 63 \\
$10-15$ & 597 & $35-40$ & 4 \\
$15-20$ & 236 & $40-45$ & 8 \\
\hline
\end{tabular}

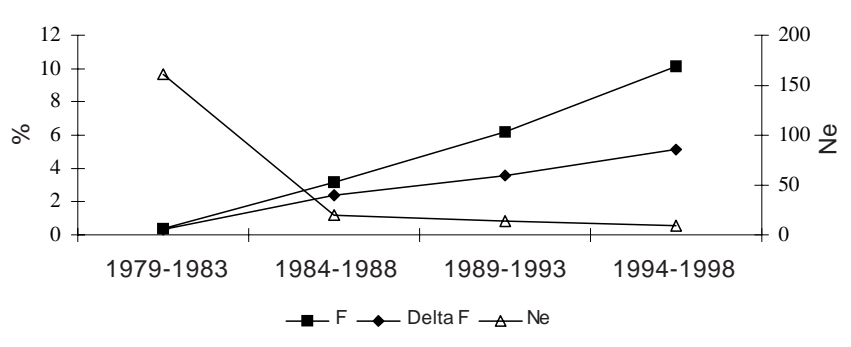

Figura 1 - Evolução do coeficiente de endogamia (F), delta $F(\Delta F)$ e tamanho efetivo populacional $\left(\mathrm{N}_{\mathrm{e}}\right)$ na raça Sindi.

Figure 1 - Inbreeding coefficient $(F)$, delta $F(\Delta F)$ and effective population size $(\mathrm{Ne})$ evolution in the Red Sindhi breed. 
A evolução das estatísticas de F pode ser vista na Figura $4 . \mathrm{OF}_{\mathrm{ST}}$ passou de $0,07 \%$, no primeiro período, para 5,65\% no último, aumentando em $7.300 \%$ seu valor, sendo este incremento resultado do aumento da relação de parentesco entre os progenitores, o que reflete acasalamentos preferenciais ocorridos no passado. $\mathrm{O}_{\text {IS }}$ passou de $0,30 \%$ para $4,74 \%$, valor que indica a existência de subdivisão na raça. Vercesi Filho et al. (2002) também relataram a existência de subdivisão populacional na raça Tabapuã, embora os valores encontrados estejam aquém dos aqui obtidos. Resultados opostos foram encontrados por Nomura et al. (2001), na raça Japanese Black, e por Faria (2002) nas raças Nelore e Nelore Mocho. Esses autores relataram a ausência de subdivisão nessas raças, ocasionada por alguns fatores, dentre esses o uso mais intenso de IA.

$\mathrm{O}$ arquivo de genealogia permitiu traçar o número médio de ancestrais por indivíduo e o número de gerações. Embora o arquivo trabalhado contivesse dados a partir de 1955, as informações citadas foram obtidas de indivíduos com pelo menos um ancestral conhecido. Em 1963 foram registradas duas fêmeas com média de 0,75 ancestral identificado, enquanto em 1998 esse número foi de 85 fêmeas registradas com cerca de 28 ancestrais e 3,7 gerações equivalentes, em média, identificadas por animal. No caso dos machos, essas estimativas não foram muito diferentes; em 1965, foi registrado um animal com apenas um ancestral identificado, ao passo que, no ano de 1998, 83 machos com número médio de gerações equivalentes e ancestrais similares aos encontrados nas fêmeas. O número máximo de gerações identificadas foi de seis para ambos os sexos. Faria (2002) encontrou raças zebuínas em que se pode traçar até 13 gerações ascendentes.

Finalizando a análise estrutural, seguem descritos na Tabela 2 os números efetivos de fundadores, de ancestrais e de genomas remanescentes calculados para essa população. Segundo Boichard et al. (1997), as análises realizadas dos parâmetros baseados na probabilidade de origem do gene são mais eficientes na predição da variabilidade genética porque são menos sensíveis a falhas ou perdas de informações dos pedigrees. Constata-se, na Tabela 2, que houve queda na magnitude dos parâmetros estimados entre os períodos, exprimindo redução na variabilidade, com a seguinte ordem de magnitude $\mathrm{N}_{\text {fun }}>\mathrm{N}_{\mathrm{anc}}>$ $\mathrm{N}_{\text {gen }}$. O $\mathrm{N}_{\text {fun }}$ avalia como o balanço esperado das contribuições dos fundadores é mantido entre as

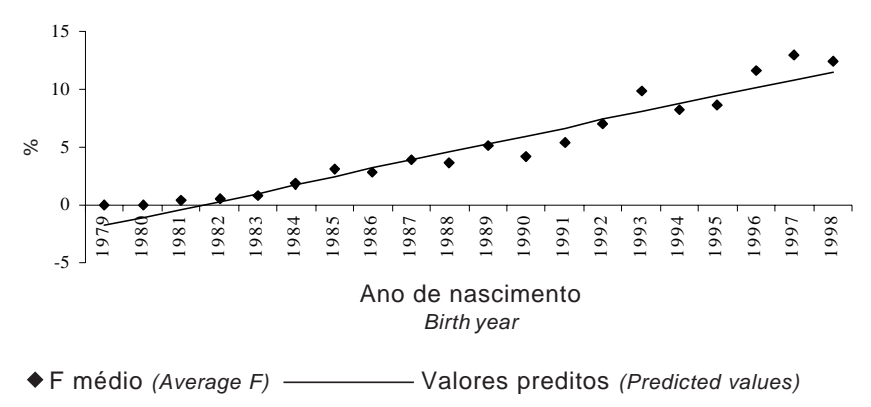

Figura 2 - Valores observados e preditos do coeficiente de endogamia anual na raça Sindi.

Figure 2 - Observed and predicted values of the annual inbreeding coefficient in the Red Sindhi breed.

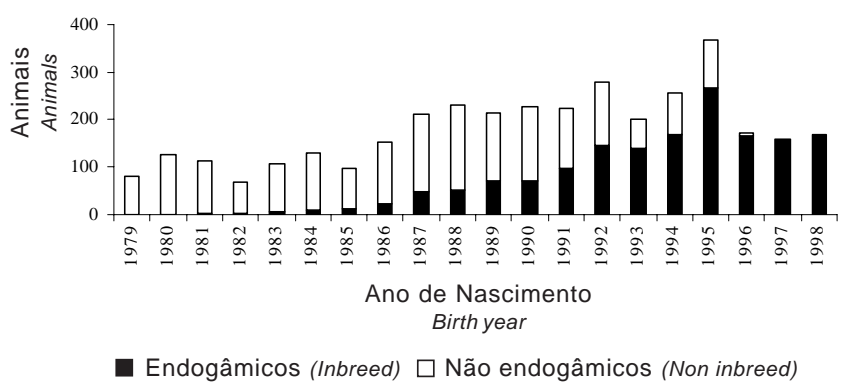

Figura 3 - Evolução anual do número de animais endogâmicos na raça Sindi.

Figure 3 - Annual evolution of the inbreed animals in the Red Sindhi breed.

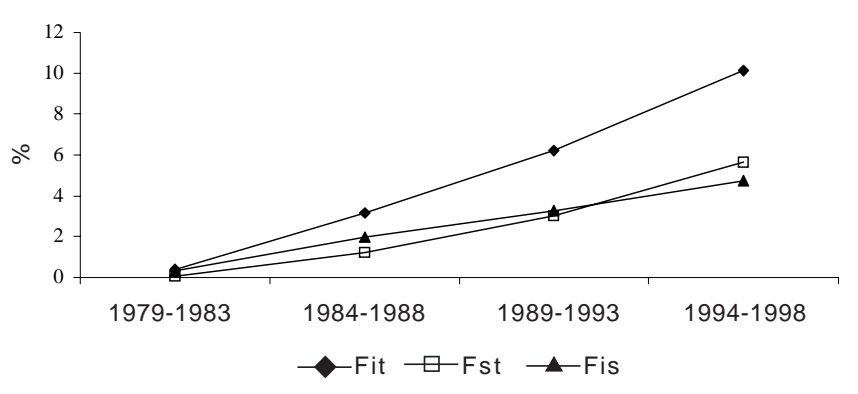

Figura 4 - Evolução das estatísticas de F na raça Sindi. Figure 4 - F statistics evolution in the Red Sindhi breed. 
gerações, levando em consideração a taxa de seleção e a variação de tamanho de família. Uma das causas de perda de genes nas populações é a diminuição do número de reprodutores em determinado período, o que é levado em consideração quando da estimação do $\mathrm{N}_{\text {anc }}$, ao passo que o $\mathrm{N}_{\text {gen }}$ avalia o número de genes fundadores que é mantido na população para determinado loco. Desse modo, o $\mathrm{N}_{\text {fun }}$ apresentou os maiores valores, por expressar somente a contribuição de fundadores, e o $\mathrm{N}_{\text {gen }}$, as menores estimativas, por considerar todas as possibilidades de perdas de alelos fundadores.

$\mathrm{O} \mathrm{N}_{\text {fun }}$ estimado no presente trabalho é o menor descrito para raças zebuínas criadas no Brasil, descritas por Faria (2002), o que pode ser atribuído ao pequeno número de fundadores e machos em uso. $\mathrm{O}$ número efetivo de ancestrais Sindi revela a predominância na utilização de alguns reprodutores, explicada por sua contribuição marginal junto à população-referência (Tabela 3).

A razão $\mathrm{N}_{\text {fun }} / \mathrm{N}_{\text {anc }}$ expressa o efeito "gargalo" e resulta da diminuição do número de reprodutores entre períodos. No rebanho Sindi, esse valor passa de 1,03 para 1,77, com valor médio de 1,52. De acordo com Vercesi Filho et al. (2002), na raça Tabapuã esse valor esteve entre 1,02 e 1,44 no primeiro e último períodos. Boichard et al. (1997) relataram razão igual a 3,0 na raça Normanda, relacionada à intensa utilização de poucos animais por meio de inseminação artificial. Embora não possam ser consideradas comparações diretas, o $\mathrm{N}_{\text {anc }}$ do último período na raça Sindi está entre os menores valores descritos na

Tabela 2 - Número efetivo de fundadores $\left(\mathrm{N}_{\text {fun }}\right)$, de ancestrais $\left(\mathrm{N}_{\text {anc }}\right)$, de genomas remanescentes $\left(N_{\text {gen }}\right)$ e razões $N_{\text {fun }} / N_{\text {anc }}$ e $N_{\text {gen }} / N_{\text {fun }}$ na raça Sindi

Table 2 - Effective number of founders $\left(N_{\text {fun }}\right)$, ancestors $\left(N_{\text {and }}\right)$, remaining genomes $\left(N_{\text {gen }}\right)$ and ratios $N_{\text {fun }} / N_{\text {anc }}$ and $N_{\text {gen }} / N_{\text {fun }}$

\begin{tabular}{ccccccc}
\hline $\begin{array}{c}\text { Período } \\
\text { Period }\end{array}$ & $\begin{array}{c}\text { Fundadores } \\
\text { Founders }^{a}\end{array}$ & $\mathrm{~N}_{\text {fun }}$ & $\mathrm{N}_{\text {anc }}$ & $\mathrm{N}_{\text {gen }}$ & $\mathrm{N}_{\text {fun }} / \mathrm{N}_{\text {anc }}$ & $\mathrm{N}_{\text {gen }} / \mathrm{N}_{\text {fun }}$ \\
\hline 1979a 1983 & 293 & 64 & 62 & 52 & 1,03 & 0,81 \\
1984 a 1988 & 297 & 47 & 31 & 26 & 1,51 & 0,55 \\
1989 a 1993 & 244 & 27 & 15 & 13 & 1,80 & 0,48 \\
1994 a 1998 & 196 & 16 & 9 & 7 & 1,77 & 0,43 \\
\hline
\end{tabular}

a Fundadores = animais com progênie, mas sem ascendência identificada.

a Founders = animals with progeny, but without identified ascendancy.

Tabela 3 - Contribuição marginal acumulada de ancestrais da raça Sindi

Table 3 - Cumulative marginal contribution of ancestors in the Red Sindhi breed

\begin{tabular}{|c|c|c|c|c|}
\hline $\begin{array}{l}\text { Proporção de alelos contribuída } \\
\text { Proportion of genes contributed }\end{array}$ & $1979-1983$ & $1984-1988$ & $1989-1993$ & $1994-1998$ \\
\hline $\begin{array}{l}\text { Primeiro ancestral } \\
\text { First ancestor }\end{array}$ & 0,0553 & 0,1277 & 0,1898 & 0,2867 \\
\hline $\begin{array}{l}\text { Segundo ancestral } \\
\text { Second ancestor }\end{array}$ & 0,0969 & 0,1964 & 0,3223 & 0,3936 \\
\hline $\begin{array}{l}\text { Terceiro ancestral } \\
\text { Third ancestor }\end{array}$ & 0,1365 & 0,2522 & 0,3741 & 0,4858 \\
\hline $\begin{array}{l}\text { Quarto ancestral } \\
\text { Fourth ancestor }\end{array}$ & 0,1717 & 0,2945 & 0,4208 & 0,5343 \\
\hline $\begin{array}{l}\text { Quinto ancestral } \\
\text { Fifth ancestor }\end{array}$ & 0,2056 & 0,3241 & 0,4501 & 0,5711 \\
\hline $\begin{array}{l}\text { Primeiros } 10 \text { ancestrais } \\
\text { First } 10 \text { ancestors }\end{array}$ & 0,3443 & 0,4303 & 0,5595 & 0,6862 \\
\hline $\begin{array}{l}\text { Primeiros } 50 \text { ancestrais } \\
\text { First } 50 \text { ancestors }\end{array}$ & 0,6237 & 0,6939 & 0,8222 & 0,8957 \\
\hline
\end{tabular}

R. Bras. Zootec., v.33, n.4, p.852-857, 2004 
literatura (Boichard et al., 1997; Sölkner et al., 1998; Vercesi Filho et al., 2002). A proporção entre $\mathrm{N}_{\text {gen }} / \mathrm{N}_{\text {fun }}$ indica a extensão do processo de deriva genética e os valores reduziram de 0,81 a 0,43 , indicando aumento nesse processo ao longo dos períodos. Vercesi Filho et al. (2002) relataram para a raça Tabapuã o valor de 0,54 entre 1994 e 1998.

Na Tabela 3, evidencia-se maior contribuição de certos animais. No último qüinqüênio, 50 animais respondem pela quase totalidade dos alelos presentes na população. Tornou-se crecente, com o passar dos qüinqüênios, a contribuição alélica de cada ancestral, exemplificada entre o primeiro e último períodos nos quais o ancestral que mais contribuiu incrementou sua participação em 500\%, detendo, no último qüinqüênio, quase $30 \%$ dos alelos na populaçãoreferência sendo que, nesse último, os cinco ancestrais mais importantes responderam por cerca de $60 \%$ dos genes.

Os resultados encontrados nesta pesquisa corroboram as descrições de redução na variabilidade genética já descritos por Faria et al. (2001) no rebanho Sindi. No referido trabalho, estes autores apresentaram os efeitos da variância de tamanho de progênie sobre o $\mathrm{N}_{\mathrm{e}}$, determinando valor crítico quanto ao número de fêmeas puras em reprodução. No presente estudo, os parâmetros determinados por meio das estatísticas de F e da probabilidade de origem do gene indicaram redução bastante acentuada da variabilidade genética da raça Sindi.

\section{Conclusões}

Os valores do coeficiente de consangüinidade $\left(\mathrm{F}_{\mathrm{IT}}\right)$ e da taxa de incremento da endogamia $(\Delta \mathrm{F})$ aumentaram entre os períodos, com concomitante redução do tamanho efetivo populacional $\left(\mathrm{N}_{\mathrm{e}}\right)$. A relação de parentesco entre os animais elevou-se conforme os valores determinados do coeficiente médio de endogamia esperado sob acasalamentos ao acaso $\left(\mathrm{F}_{\mathrm{ST}}\right)$. A magnitude do índice de subdivisão genética $\left(\mathrm{F}_{\mathrm{IS}}\right)$ indicou a existência de subpopulações. Os parâmetros estimados do número efetivo de fundadores $\left(\mathrm{N}_{\text {fun }}\right)$, de ancestrais $\left(\mathrm{N}_{\text {anc }}\right)$ e de genomas remanescentes $\left(\mathrm{N}_{\mathrm{gen}}\right)$ decresceram entre os períodos e as relações entre eles $\left(\mathrm{N}_{\text {fun }} / \mathrm{N}_{\text {anc }}\right.$ e $\left.\mathrm{N}_{\text {gen }} / \mathrm{N}_{\text {fun }}\right)$ indicaram o aumento do efeito gargalo e do processo de deriva genética na população avaliada.

\section{Agradecimento}

À ABCZ, pela concessão dos dados para este trabalho, realizado com apoio do CNPq, CAPES e FAPEMIG.

\section{Literatura Citada}

ABCZ. "Estatísticas”, http://www.abcz.org.br, acessado em 10/ 04/2001.

BOICHARD, D.; MAIGNEL, L.; VERRIER, É. The value of using probabilities of gene origin to measure genetic variability in a population. Genetics, Selection and Evolution, v.29, p.5-23, 1997.

CROW, J.F.; KIMURA, M. An introduction to population genetics theory. New York: Harper and Row, 1970. 591p.

FALCONER, D.S.; MACKAY, T. Introduction to quantitative genetics. 4.ed. London: Longman Group Ltda, 1996. 464p.

FARIA, F.J.C. Estrutura genética das populações zebuínas brasileiras registradas. Belo Horizonte: Universidade Federal de Minas Gerais, 2002. 177p. Tese (Doutorado em Ciência Animal) - Universidade Federal de Minas Gerais, 2002.

FARIA, F.J.C.; VERCESI FILHO, A.E.; MADALENA, F.E. et al. Parâmetros populacionais do rebanho Sindi registrado no Brasil. Revista Brasileira de Zootecnia, v.30(6S), p.1989-1994, 2001.

GODDARD, M.G.; SMITH, C. Optimum number of bull sires in dairy cattle breeding. Journal of Dairy Science, v.73, p.1113-1122, 1990.

LACY, R.C. Analysis of founder representation in pedigrees: founder equivalents and founder genome equivalents. Zoo Biology, v.8, p.111-123, 1989.

LEITE, P.R.M.; SANTIAGO, A.A.; NAVARRO FILHO, H.R. et al. Sindi: Gado vermelho para o semi-árido. João Pessoa: EMEPA - PB / Banco do Nordeste, 2001. 147p.

MEUWISSEN, T.H.E.; WOOLLIAMS, J. Effective sizes of livestock populations to prevent a decline in fitness. Theoretical and Applied Genetics, v.89, p.1019-1026, 1994.

NICHOLAS, F.W. Size of population required for artificial selection. Genetical Research, v.35, p.85-105, 1980.

NOMURA, T.; HONDA, T.; MUKAI, F. Inbreeding and effective population size of Japanese Black cattle. Journal of Animal Science, v.79, p.366-370, 2001.

SÖLKNER, J.; FILIPCIC, L.; HAMPSHIRE, N. Genetic variability of populations and similarity of subpopulations in Austrian cattle breeds determined by analysis of pedigrees. Animal Science, v.67, p.249-256, 1998.

VERCESI FILHO, A.E.; FARIA, F.J.C.; MADALENA, F.E. et al. Estrutura populacional do rebanho Tabapuã registrado no Brasil. Arquivo Brasileiro de Medicina Veterinária e Zootecnia, v.54, n.6, p.609-617, 2002.

WRIGHT, S. The interpretation of population structure by F-statistics with special regards to systems of mating. Evolution, v.19, p.395-420, 1965.

Recebido em: 22/04/03 Aceito em: 09/10/03 